EPJ Web of Conferences 52, 06007 (2013)

DOI: 10.1051/epjconf/20135206007

(C) Owned by the authors, published by EDP Sciences, 2013

\title{
The GiBUU transport model
}

\author{
Janus Weil ${ }^{1, a}$, Ulrich Mosel ${ }^{1}$ \\ ${ }^{1} \mathrm{JLU}$ Giessen, Germany
}

\begin{abstract}
We give an overview over the hadronic transport model GiBUU as a simulation tool for hadronic and electroweak reactions on nuclei over a wide energy range [1]. The model is able to handle hadron-, photon- and lepton-induced reactions as well as nucleus nucleus collisions from sub-GeV energies up to hundreds of $\mathrm{GeV}$. After a general introduction of the model, we discuss its possible application to cosmic ray air showers.
\end{abstract}

\section{References}

[1] O. Buss et al, Phys. Rept. 512 (2012) 1-124

Slides

The slides of the talk can be found on the website of the symposium ISVHECRI 2012:

https://indico.desy.de/conferenceOtherViews.py?view=standard\&confId=4594

ajanus.weil@theo.physik.uni-giessen.de

This is an Open Access article distributed under the terms of the Creative Commons Attribution License 2.0, which permits unrestricted use, distribution, and reproduction in any medium, provided the original work is properly cited. 